\title{
Discovery of genetic variants for fatty acid binding proteins of pig (Brief Report)
}

\author{
Entdeckung genetischer Varianten für Fettsäure \\ bindenden Proteine vom Schwein (Brief Report)
}

Hoyoung Chung

Animal Genetic Improvement Division, National Institute of Animal Science, Cheonan, South Korea

\section{Background}

Back fat thickness (BFT) and intramuscular fat (IMF) contents are known as major issues affecting meat performance. Several types of fatty acid-binding proteins (FABPs), which involve signal transduction pathways, are abundantly presented in tissues such as intestine, liver, kidney, mammary gland, heart, and red skeletal muscle (Nechtelberger et al. 2001). FABPs have been reported to be differentially expressed genes during porcine adipogenesis (Samulin et al. 2008) and related to fat deposition (Szczerbal et al. 2007). Accordingly FABPs may be candidate genes to explain variation of fat related traits in pigs. Therefore, it is an essential process to search genetic variants that may provide useful genetic information to study associations with quantitative loci (QTL).

\section{Procedure}

Amplification primers for FABP1, 2, 4, 5, and 7 genes were designed based on sequences from the GenBank (Table 1). PCR mixtures used were made up of $2 \mu \mathrm{l}$ of $10 \mathrm{X}$ reaction buffer $(10 \mathrm{mM}$ Tris, $\mathrm{pH} 8.3,50 \mathrm{mM} \mathrm{KCl}, 0.1 \%$ Triton $\mathrm{X}-100$, and $1.5 \mathrm{mM} \mathrm{MgCl}$ ), $25 \mathrm{mM}$ of dNTP, $10 \mathrm{pmol}$ of each primer, $50 \mathrm{ng}$ of genomic DNA, and 0.2 units of Taq DNA polymerase (Gibco BRL, Grand Island, NY) in a final volume of $20 \mu \mathrm{l}$. After heating at $95^{\circ} \mathrm{C}$ for $2 \mathrm{~min}$, a total of $35 \mathrm{cycles}$ were adapted for denaturation at $94^{\circ} \mathrm{C} / 1 \mathrm{~min}$, annealing at 51 to $59^{\circ} \mathrm{C} / 1 \mathrm{~min}$, and polymerization at $72^{\circ} \mathrm{C} / 1.5 \mathrm{~min}$. After cleaning up PCR products using a PCR clean up kit (Nucleogen, Korea), the direct sequencing was performed with Big-dye terminator version 3.1 and an $A B I 3730 X L$ Genetic Analyzer. Each experiment was duplicated for PCR amplification and sequencing reactions to minimize base calling errors. After identification of genetic variants, SNPs were detected for 355 Yorkshire pigs using the sequenom mass array system.

\section{Results}

This study aimed to search single nucleotide polymorphisms (SNPs) in FABPs as molecular markers accounting for variation of fat mechanisms of pigs. As shown in Table 2, a total of 26 SNPs were identified using 355 Yorkshire pigs, and the sequences with the newly identified SNPs were submitted to GenBank with accession numbers (FABP1, FABP2, FABP4, FABP5, 


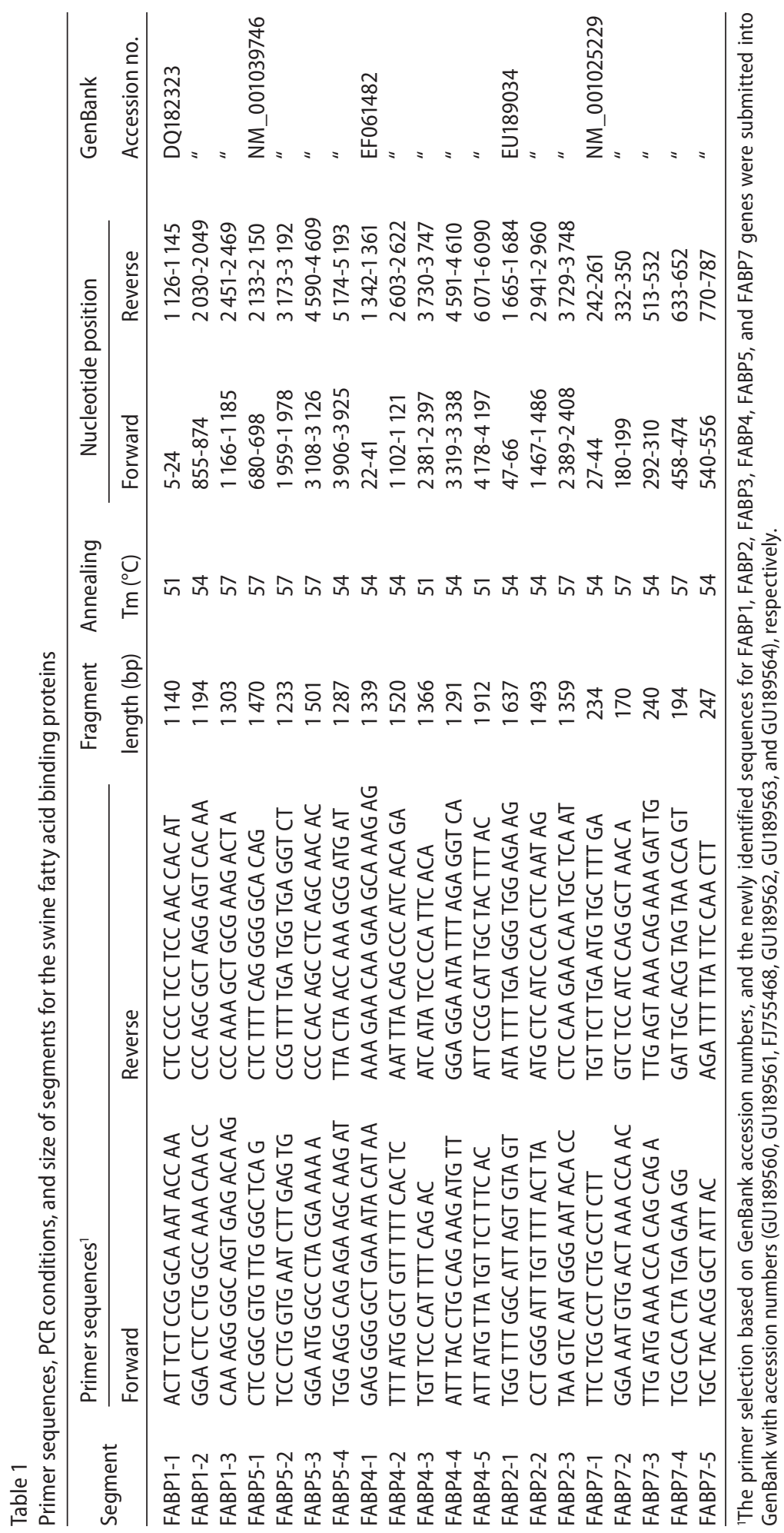




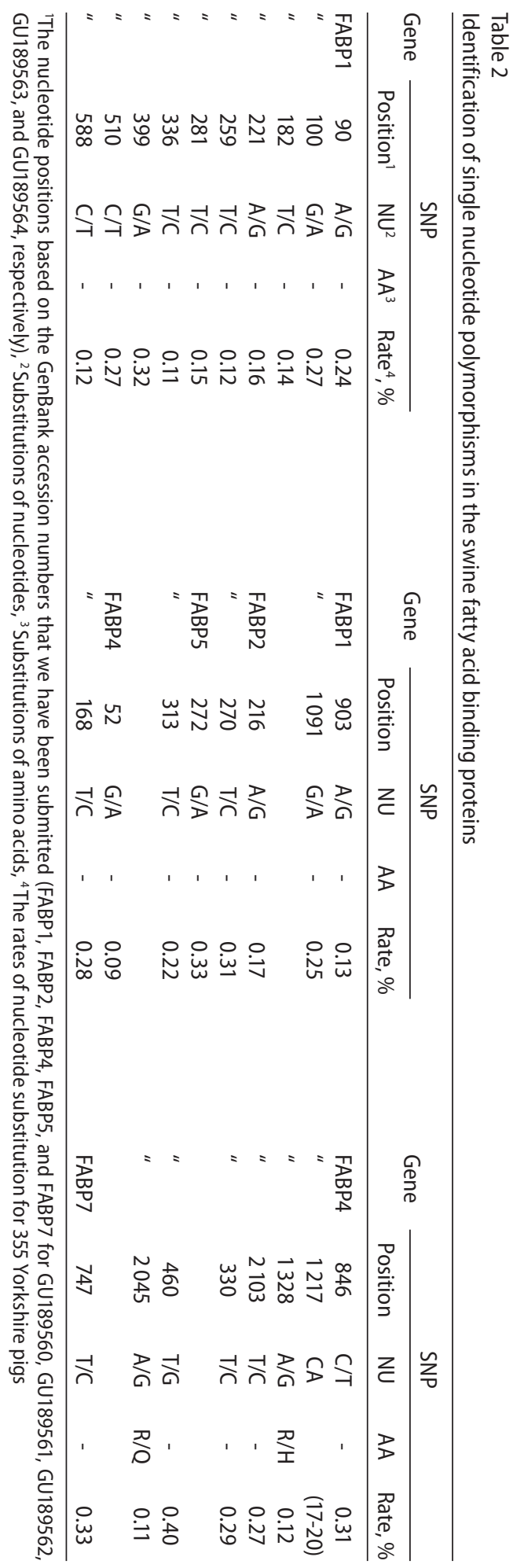


and FABP7 for GU189560, GU189561, GU189562, GU189563, and GU189564, respectively). Substitutions of amino acids detected with 2 SNPs at positions 1,328 (R/H) and 2,045 (R/Q) in FABP4 and FABP5 gene, respectively, and some of the amino acids revealed conservative patterns showing that the polymorphisms have not been observed in other species using the blast search. We also found di-repeat sequences, showing polymorphisms (CA $)_{17-20}$. The identified SNPs are the first report to help understanding of genetic structures for pig populations regarding fat related traits.

The existence of mutation sites in coding regions of $F A B P$ genes may give useful genetic information due to the relation to fat deposition (Szczerbal et al. 2007). In addition, as candidate genes associated with fatness (Estelle et al. 2009, Mercade et al. 2006), either genotypes or haplotypes of FABP genes in this analysis may help animal breeders when they select animals and change genetic structures in pig populations for commercial purposes.

\section{Acknowledgements}

This work was supported in part by government funds appropriated to the annual research project »Proteomic analysis for the differentially expressed genes and identification of genetic markers related to animal growth in commercial pig population« at National Institute of Animal Science in Korea.

\section{References}

Nechtelberger D, Pires V, Söolknet J, Stur Brem G, Mueller M, Mueller S (2001) Intramuscular fat content and genetic variants at fatty acid-binding protein loci in Austrian pigs. J Anim Sci 79, 2798-2804

Samulin J, Berget I, Lien S, Sundvold H (2008) Differential gene expression of fatty acid binding proteins during porcine adipogenesis. Comp Biochem Physiol B Biochem Mol Biol 151, 147-152

Szczerbal I, Chmurzynska A, Switonski M (2007) Cytogenetic mapping of eight genes encoding fatty acid binding proteins (FABPs) in the pig genome. Cytogenet Genome Res 118, 63-66

Estelle J, Mercade A, Pérez-Enciso M, Pena RN, Silio L, Sanchez A, Folch JM (2009) Evaluation of FABP2 as candidate gene for a fatty acid composition QTL in porcine chromosome 8. J Anim Breed Genet 126, 52-58

Mercade A, Perez-Enciso M, Varona L, Alves E, Noguera JL, Sanchez A, Folch JM (2006) Adipocyte fatty-acid binding protein is closely associated to the porcine FAT1 locus on chromosome 4, J Anim Sci 84, 2907-2913

Received 17 June 2010, accepted 1 March 2011.

Corresponding author:

Hoyoung Chung

email: chung133@korea.kr

Animal Genetic Improvement Division, National Institute of Animal Science, Cheonan, Chungnam, 330-801, South Korea 